\title{
Mechanical Properties of Submicron Glass Fiber Reinforced Vinyl Ester Composite
}

\author{
Nguyen T. T. Nhan ${ }^{1 *}$, K. Obunai ${ }^{1}$, K. Okubo' ${ }^{1}$, O. Shibata ${ }^{2}$, H. Tomokuni ${ }^{2}$, Y. Fujita ${ }^{2}$ \\ ${ }^{1}$ Department of Mechanical and Systems Engineering, Graduate School/Faculty of Science and Engineering, Doshisha University, \\ Kyotanabe, Kyoto, Japan \\ ${ }^{2}$ DIC Corporation, Tokyo, Japan \\ Email: ^thanhnhandec@gmail.com
}

How to cite this paper: Nhan, N.T.T., Obunai, K., Okubo, K., Shibata, O., Tomokuni, H. and Fujita, Y. (2019) Mechanical Properties of Submicron Glass Fiber Reinforced Vinyl Ester Composite. Open Journal of Composite Materials, 9, 365-377.

https://doi.org/10.4236/ojcm.2019.94023

Received: August 30, 2019

Accepted: October 9, 2019

Published: October 12, 2019

Copyright (c) 2019 by author(s) and Scientific Research Publishing Inc. This work is licensed under the Creative Commons Attribution International License (CC BY 4.0).

http://creativecommons.org/licenses/by/4.0/

\begin{abstract}
Vinyl ester (VE) resin inherently has intrinsic brittleness due to its high cross-link density. To improve mechanical performance, micro/nano fillers are widely used to modify this matrix. In present study, glass fiber in submicron scale at low contents was added into VE to prepare submicron composite (sMC). The impact resistance of un-notched sMC degraded with the increase of sGF content while that of notched-sMC remained the unchanged. Flexural properties of sMCs also were the same with that of neat resin. The results of Dynamic mechanical analysis (DMA) test showed the slight increase of storage modulus and the decrease of tan delta value in the case of sMC compared to those of un-filled matrix. However, the Mode I fracture toughness of sMC improved up to $26 \%$ and $61 \%$ corresponding to 0.3 and 0.6 $\mathrm{wt} \%$ glass fiber used. The compact tension sample test suggests that there is the delay of crack propagation under tensile cyclic load in resin reinforced by submicron glass fiber. The number of failure cycle enlarged proportionally with the increment of sGF content in matrix.
\end{abstract}

\section{Keywords}

Submicron Glass Fiber, Vinyl Ester Resin (VE), Micro-Nano Composite, Submicron Composite, Modify

\section{Introduction}

Vinyl ester resins are typically formulated from styrene and a condensation product of methacrylic acid with an epoxy. Because the reactive double bonds are at the ends of relatively long chains, their cross-link density tends to be lower than the standard polyester resins. Therefore, it may also be regarded as filling 
the gap between epoxy resin and polyester resin in both sides of mechanical property as well as effective economy [1] [2] [3] [4]. Thanks to good toughness, excellent resistance, good mechanical properties, outstanding heat performance, and flexible processibility compared to unsaturated polyester, VE is being increasingly used in solvent storage tanks, sewer pipes, ship and boat construction, coating, automobile structural parts, swimming-pool [5] [6]. Similar to other thermosets, pure vinyl ester resin is inherently brittle due to their highly cross-linked structure. One approach to increase its performance is to modify with fillers at micro/nano scale [7]-[12]. There is a large number of studies conducted to investigate properties of vinyl ester resin reinforced by micro/nano particles. Vahid Arabli et al. studied in curing kinetics, modeling, mechanical properties and thermal stability in graphene oxide/vinyl ester resin nanocomposite [13]. They claimed that with a low content of graphene oxide $(0.3 \%)$, the matrix became stiffer while the glass transition temperature shifted to a higher value. Dipa Ray used fly ash had a particlesize distribution in the range of 76 to $152 \mu \mathrm{m}$ to fill in VE matrix [14]. Auad et al. modified vinyl ester resin of different molecular weights by rubber. The research group claimed that the addition of elastomers produces toughening of the networks, but at the same time a reduction of their mechanical properties such as flexural modulus and compression yield stress [15]. S. Grishchuk et al. investigated about structure and properties of vinyl ester resins modified with organophilic synthetic layered silicates bearing non- and co-reactive intercalants. They found that fracture toughness $(\mathrm{Kc})$ and energy $(\mathrm{Gc})$ were markedly improved with increasing organophilic synthetic layered silicates amount [16]. However, along with restriction of loading content in polymer, the size of nano fillers is close to the molecular scale, leading to detrimental effects on properties of filled system because of intercalating of nano particles and base material [17] Therefore, submicron particles have been considered as filled-gap material between nano and micro filler in recent years. In spite of that, in the best authors' knowledge, there was still very few literature about using micro-nano filler for polymer matrix [18] [19] [20]. In this study, the submicron glass fiber (sGF) with diameter in the range of micro-nano scale used to reinforce vinyl ester resin at low content to facilitate using experimental data for further research of carbon fiber composite after that. Mechanical properties were characterized to access effects of sGF on submicron composite (sMC) system.

\section{Materials and Experiments}

\subsection{Materials}

The general vinyl ester resin (VE) supplied by DIC Corporation, gel time of 60 minutes. The hardener and promoter (DIC Corp) were Percure AH (acetyl acetone peroxide) and RP-330 (general cobalt accelerator) used at the weight ratio of $1 \%$ and $0.2 \%$, respectively against weight of VE. The submicron glass fiber (sGF) was from Nippon Muki Co., Ltd, Japan with diameter in the range of 0.4 
to $2.4 \mu \mathrm{m}$ and length of 20 to $200 \mu \mathrm{m}$ and minority of length reaches $1 \mathrm{~mm}$ (Figure 1). All materials used without any further treatment.

\subsection{Preparation of Sub-Micron Composite}

After eliminating absorbed moisture in the dry oven for 12 hours at $60^{\circ} \mathrm{C}$, sGF was put into the stainless steel cup of the homogenizer and mixed with resin at speed of $5000 \mathrm{rpm}$ for 30 minutes followed by adding hardener and promoter and mixed again by the plastic bar. The mixture was applied vacuum pressure to remove air bubbles trapped in resin during mixing until no bubbles remained on the surface of resin cup when observed by naked-eyes. To limit styrene evaporated, the vacuum time and vacuum pressure were controlled. The mixture of resin and glass fiber was gently poured into the mould, silently kept for $15 \mathrm{~min}$ utes to facilitate bubbles escaped, followed by casting process in the dry oven for 3 hours at $80^{\circ} \mathrm{C}$ and post-cured at $100^{\circ} \mathrm{C}$ with the same time. The plate of sMC after that was cut into coupon specimens by the diamond cutter. The plate of neat resin also prepared in the same mould with the same processing conditions.

\subsection{Izod Resistance Test}

The impact resistance test of neat resin and sMC was performed using the pendulum testing device according to the standard ASTM D4812 for unnotched sample and D256 for notched-sample. The test was conducted when the hammer impacted onto the edge of specimen for both of the notched and the un-notched. At least 10 specimens were used for each sample group.

\subsection{Three-Point Bending Test}

The three-point bending test was carried out on the Autograph $100 \mathrm{kN}$ tester (Shimadu Corp) at the speed of $2 \mathrm{~mm} / \mathrm{min}$, the support length of $60 \mathrm{~mm}$ following the standard ASTM D790. At least five specimens were prepared for each condition. The yield strength as well as young modulus were calculated by determining $0.2 \%$ offset yield stress from stress-strain graph achieved on computer during the test.

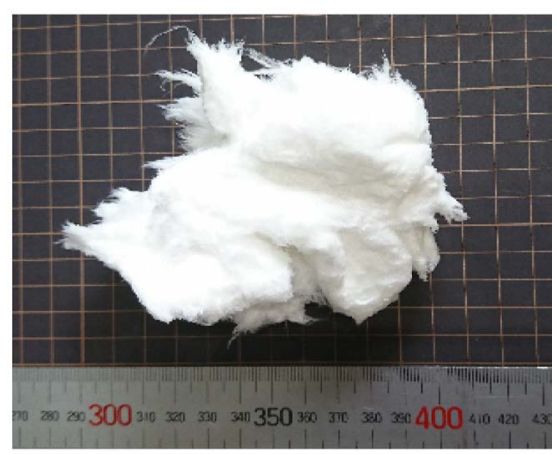

(a)

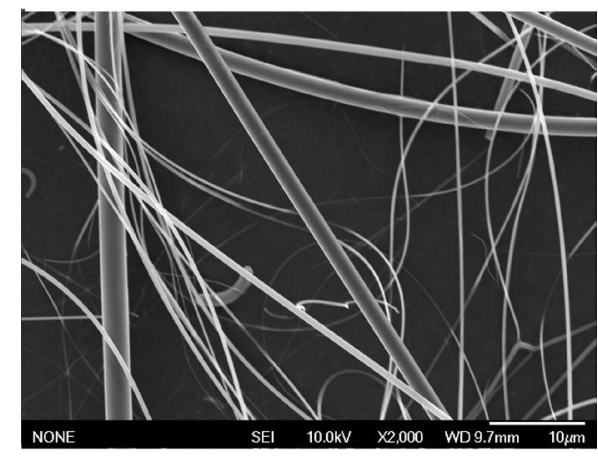

(b)

Figure 1. Submicron glass fiber as in using condition (a) and under observation by scanning electron microscope (b). (Figure 1(b) Source: Nippon Muki Co., Ltd.). 


\subsection{Dynamic Mechanical Analysis}

Dynamic mechanical analysis was performed on the DMA 7100 analyzer (Hitachi) using the tensile mode. In this study, samples were cut into small pieces with dimensions of $40 \times 10 \times 1 \mathrm{~mm}^{3}$ and the gage length of $20 \mathrm{~mm}$. The digital Vernier calliper was used to measure the dimension of the specimens before testing. The test conditions included the oscillation frequency of $1 \mathrm{~Hz}$, the range of temperature from $40^{\circ} \mathrm{C}$ to $180^{\circ} \mathrm{C}$ and the ramping speed of $3^{\circ} \mathrm{C} / \mathrm{min}$.

\subsection{Preparation of Plain Strain Fracture Toughness Sample}

To characterize the toughness of neat VE and SMC in terms of the critical-stress-intensity factor $\left(\mathrm{K}_{\mathrm{Ic}}\right.$ ), the Single Edge Notch Bending (SENB) geometry samples were prepared. The SENB was cut from the casted resin plate with the sharp-notch was created by tapping the edge of specimen to a round-cutting saw and the natural crack was generated by tapping on a fresh razor blade placed in the notch. The dimensions of specimens of $45 \times 40 \times 5 \mathrm{~mm}^{3}$ and notch length of $5 \mathrm{~mm}$ were prepared.

\subsection{Scanning Electron Microscope (SEM) Observation}

Dispersed statement of sGF inside matrix after mixing as well as fracture surfaces of specimens after tests were observed by SEM equipment JSM 7001FD. Prior to SEM observation, all specimens were subjected to sputter coating of a thin layer of gold to avoid electrical charging.

\subsection{Preparation of Compact Tension Sample}

The compact tension (CT) sample was drawn up by pouring resin into silicone molds followed by the processing of curing and post-curing in dry oven. For the sake of understanding resistance against crack propagation in matrix, a cyclic tension load was applied on samples at maximum load of $150 \mathrm{~N}$, load ratio of 0.2 and frequency of applied load was $1 \mathrm{~Hz}$. The geometry of CT sample was shown as in Figure 2.

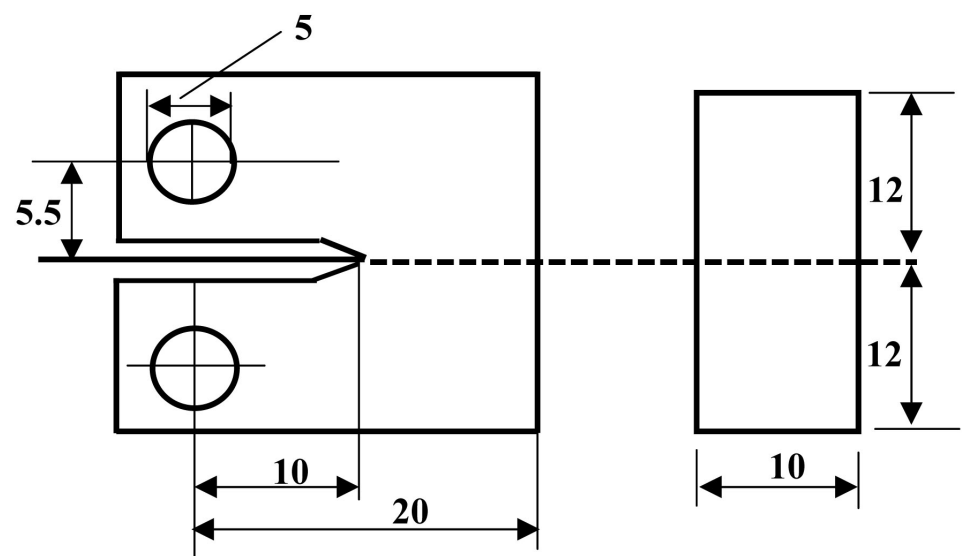

Figure 2. Geometry of CT-specimen according to ASTM D5045. 


\section{Results and Discussion}

\subsection{Dispersion of SGF in Resin}

Compared to neat resin matrix, it can be seen that the submicron glass fiber was well-dispersed inside VE matrix of composite (Figure 3(a) and Figure 3(b)). The length as well as the diameter of glass fiber after mixing also found was pretty different. This proves that conventional mixing technique is suitable for distributing sGF into vinyl ester resin and the aspect ratio of glass fiber in VE matrix varies in a large range.

\subsection{Izod Impact Resistance}

The Izod impact resistance of sMC decreased with the addition of sGF in un-notched samples (see Figure 4). As mentioned by Chris DeArmitt [21], stresses concentrate around filler particulates which causes un-homogeneousness of filled system and then plays a role as flaws deteriorate the impact resistance of material. In the case of sGF, because of the large change of the aspect ratio, the larger length the larger stress concentration. These results also are good agreement with that of DMA in later section while the energy dissipation ability degrades by adding of sGF. Whereas, the notched impact resistance was the same with all contents of sGF. Consequently, the ratio of the notched to the un-notched values decreases in the order of decreasing of sGF content in SMC: $0.6 \mathrm{wt} \%>0.3 \mathrm{wt} \%>0.0 \mathrm{wt} \%$. In other words, this indicates increasing the content of sGF in sMC, material becomes more sensitive to scratches or sharp features in the part design that may act like notches.

\subsection{Flexural Properties}

Figure 5 shows bending properties of sMC at different contents of sGF reinforcement. In general, there was no significant change in bending strength, yield strength as well as Young modulus when comparing those of neat resin with sMC. The tress-strain curves also point out the linear elastic behaviour of sMC under flexural load was almost the same regardless the concentration of glass

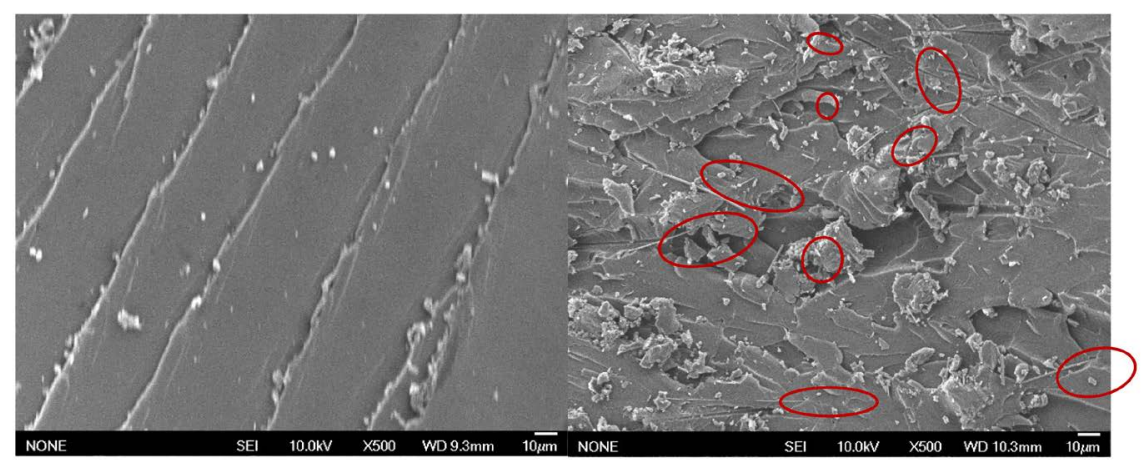

(a)

(b)

Figure 3. SEM images of fracture surface after fracture toughness test of (a) neat resin and (b) $0.6 \mathrm{wt} \% \mathrm{sGF}$ composite show the good dispersion of glass fiber in matrix. 


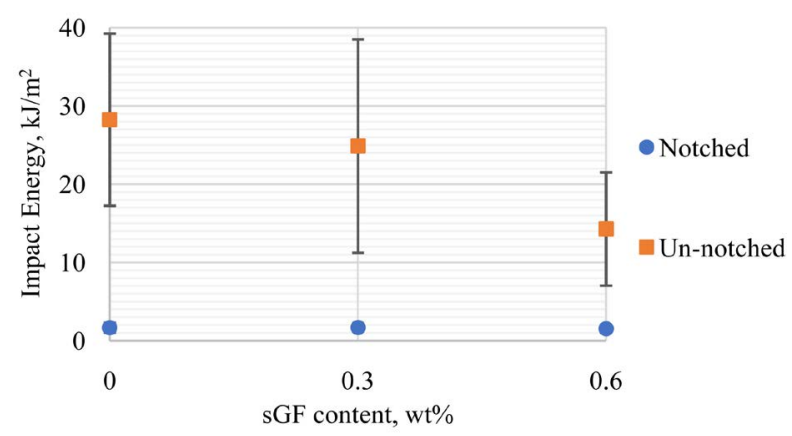

Figure 4. Izod impact resistance of sMC with respect to sGF contents.

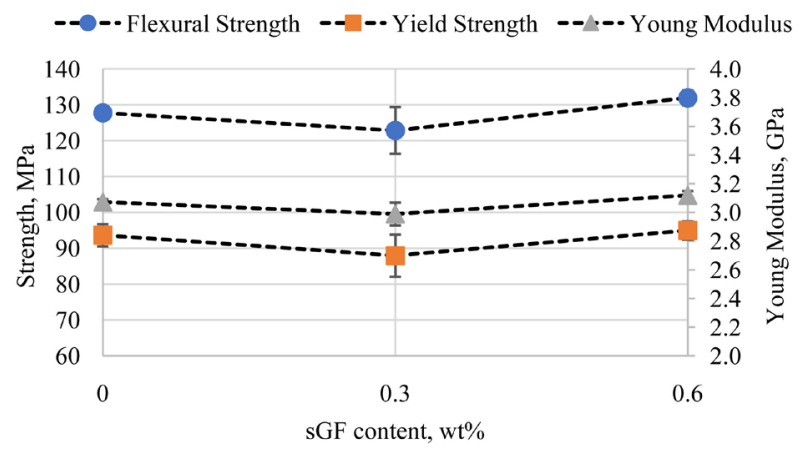

Figure 5. Bending properties of sMC with respect to sGF contents.

fiber (see Figure 6). Normally, the fillers with high aspect ratio such as glass fiber and carbon fiber have high effectiveness in elevating flexural modulus as well as yield strength [21], but there was not the similar observation in this case. It might be caused by the low content of sGF used in VE matrix.

\subsection{Dynamic Mechanical Property}

As can be seen from the peak of the loss modulus curve as well as that of tan delta, the glass transition temperature $\left(\mathrm{T}_{\mathrm{g}}\right)$ of resin was unchanged regardless the presence of sGF (Figure $7(b)$ and Figure $7(c)$ ). This indicates the fact that the cross-link density of polymer is not affected by sGF addition. However, the storage modulus of sMC was slightly higher than that of neat resin in the area far below $\mathrm{T}_{\mathrm{g}}$ (from $40^{\circ} \mathrm{C}-85^{\circ} \mathrm{C}$ ). The damping characteristic of resin also decreased with the increase of $\mathrm{sGF}$ content. It might be filler particulates absorb polymer chains into its surface, restrict the mobility of matrix molecular chains result in increasing of the elastic behaviour.

\subsection{Fracture Toughness}

The critical stress intensity factor of sMC was improved $26 \%$ and $61 \%$ corresponding to 0.3 and $0.6 \mathrm{wt} \%$ glass fiber used in comparison with that of neat VE, as can be seen in Figure 8. The SEM observation revealed that the fractured surface of neat VE was smooth and glassy with micro-flow lines while that of sMC became rougher with lots of tortuous micro cracks. The existence of sGF (inside the black circles at Figure 9(b)) was also clearly observed at fractured surface of 


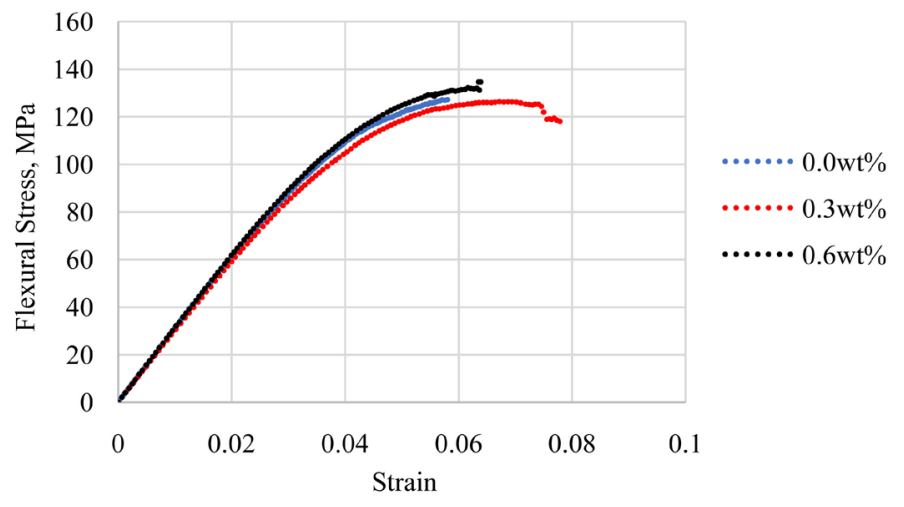

Figure 6. Typical stress-strain curves of sMC with respect to sGF contents.

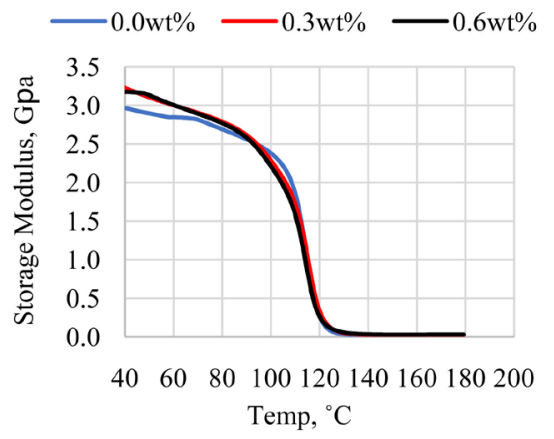

(a)

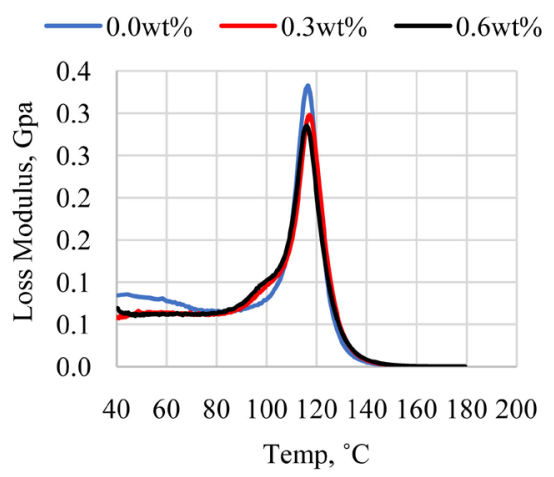

(b)

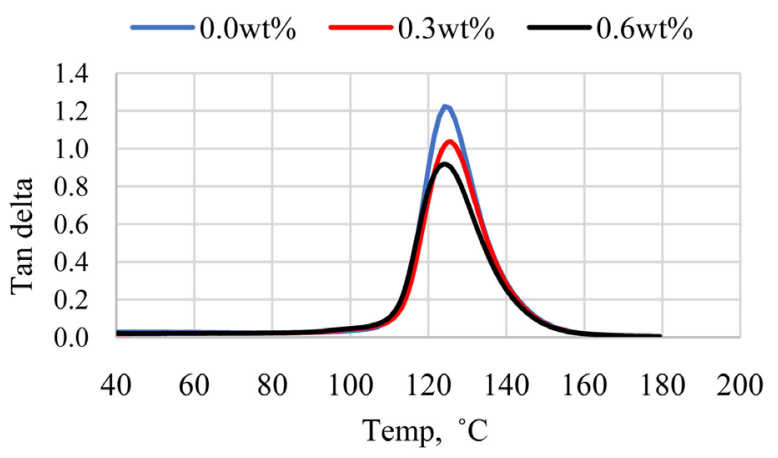

(c)

Figure 7. DMA results of sMC with respect to the different contents of sGF (a) Storage Modulus; (b) Loss Modulus and (c) Tan delta. 


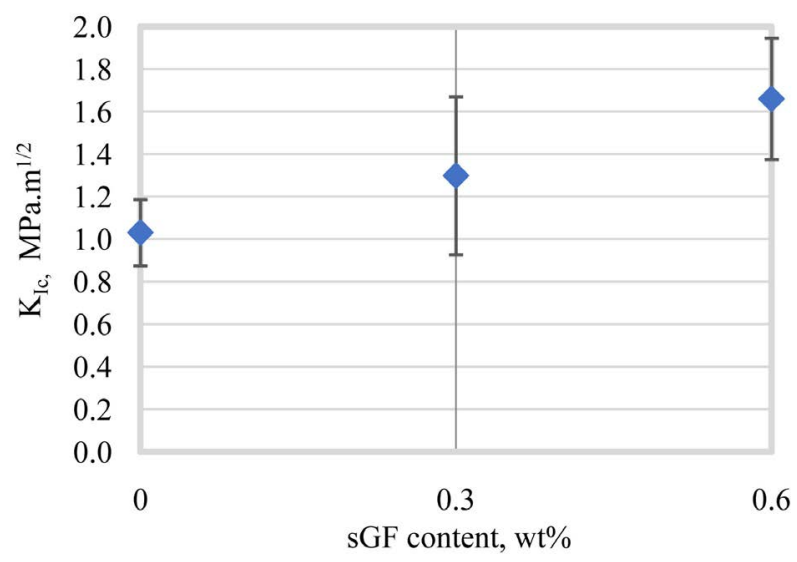

Figure 8. The fracture toughness of resin with respect to sGF content.

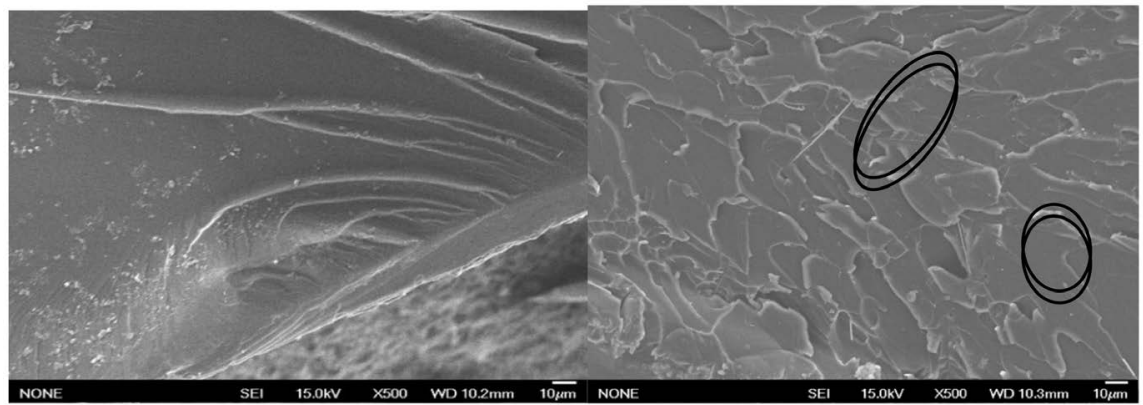

(a)

(b)

Figure 9. Fractured surface SEM images of (a) neat resin and (b) sMC with $0.6 \mathrm{wt} \%$ glass fiber after fracture toughness test.

sMC. These results suggest that the fracture toughness of matrixis effectively improved by mechanical bridging of added sGF at crack front.

\subsection{Resistance against Crack Propagation}

The fatigue life of sMC under cyclic loading condition significantly improved compared to that of neat resin (see Figure 10). The increase in the number of failure cycle was directly proportional to the content of glass fiber inside sMC. In order to better understand the extending mechanism of sGF in composite, the fracture surfaces of specimens at zone ahead of the crack tip were observed using SEM images (Figure 11). In the case of neat resin, fracture surface showed the brittle behavior with micro crack lines like river marks appeared nearly parallel along with the increasing of testing cycle. Whereas, it was not found the parallel lines of micro cracks in fracture surface of sMC. The manner was the same with that of sMC in fracture toughness test: the fracture surface became rougher, cracks were tortuous and overlapped. From parallel cracks in neat VE become indiscriminative cracks in sMC, this change can be explained by deflection of cracks thanks to existence of glass fibers in the following discussion. Besides, the de-bonding of SGF caused the considerable deformation of matrix because of forming of fishbone-shapes as can be seen in Figure 11(e). 


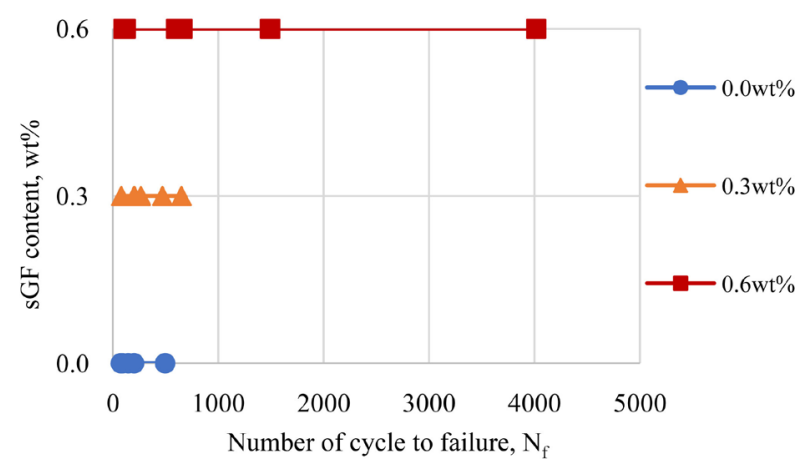

Figure 10. The number of cycle to failure of neat resin and sMC specimens under tension-tension loading condition.

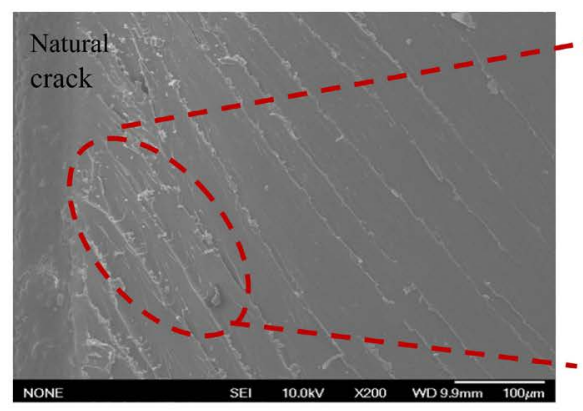

(a)

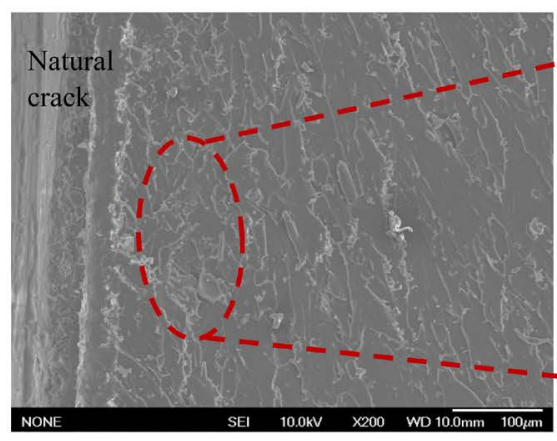

(c)

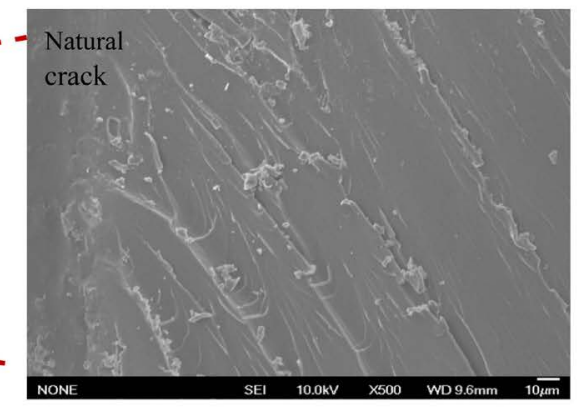

(b)

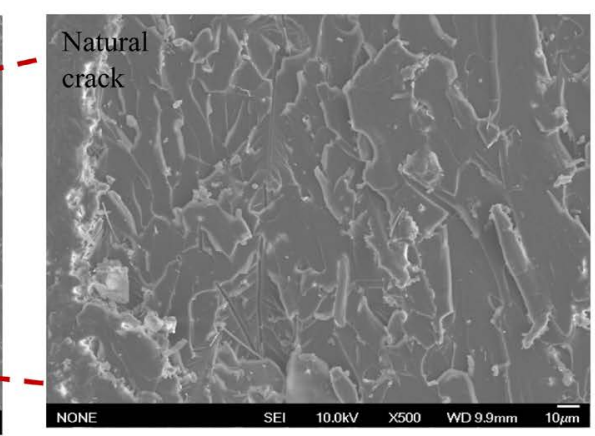

(d)

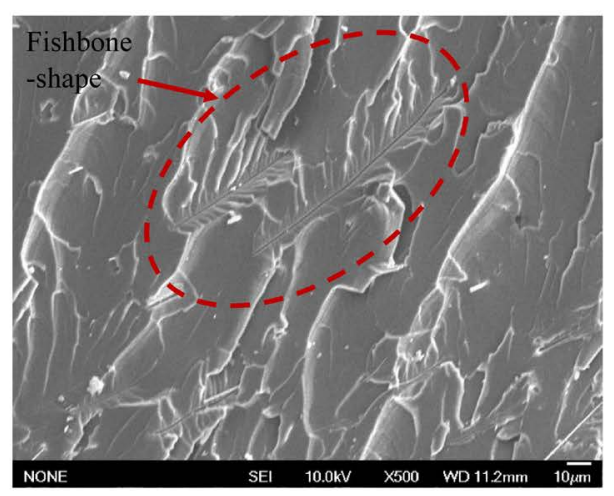

(e)

Figure 11. The SEM images of fracture surface of specimens under tension-tension load after test: ((a) and (b)) neat VE; ((c) and (d)) sMC at $0.6 \%$ sGF, (e) sMC at $0.3 \%$ sGF with fishbone-shape observed clearly. 
Along with SEM images, the fracture surface of specimens also was used to observe the propagation of striations under the fatigue load by the lazer microscope (see Figure 12). With sMCs, the evidence of crack deflection is obviously detected at branched-off positions of crack growth lines (blue circles). As mentioned by J. Petit [22], the striation spacing notifies observer the crack growth rate during a cycle. Figure 13 shows the striation spacing on the fracture surface of neat VE and sMCs, increasing the glass fiber content in matrix decreases the distance between adjacent striations and therefore, declines the crack growth

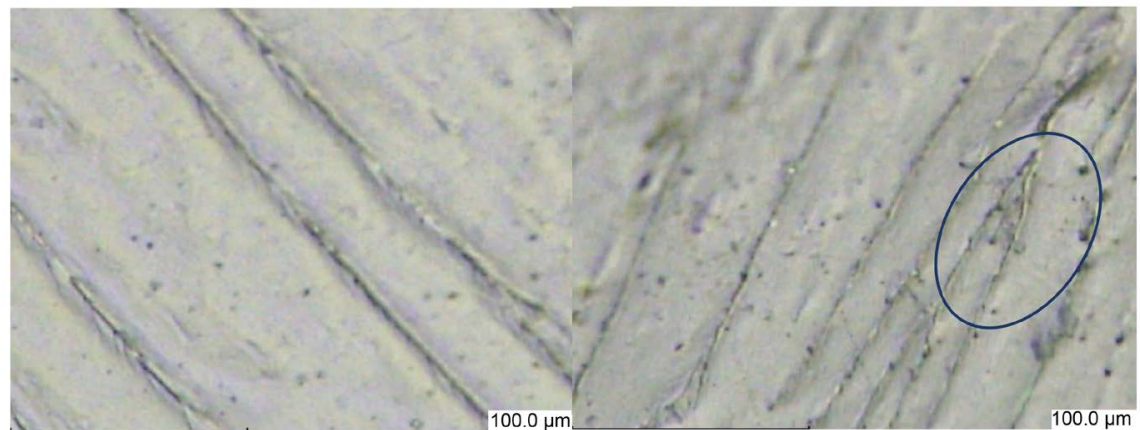

(a)

(b)

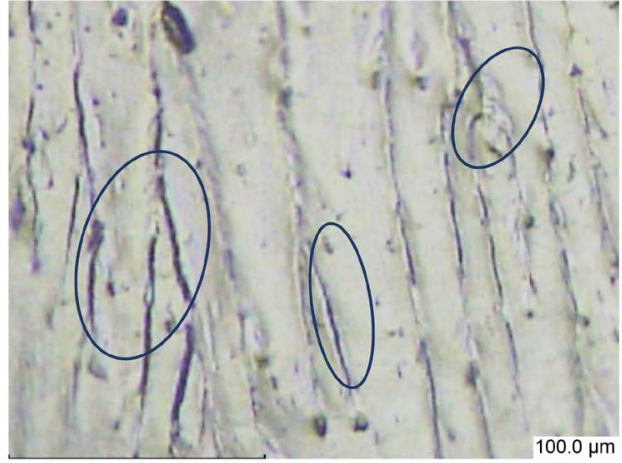

(c)

Figure 12. Lazer microscope images of fracture surface of (a) neat VE; (b) sMC at 0.3 wt $\%$ and (c) sMC at $0.6 \mathrm{wt} \%$ of sGF.

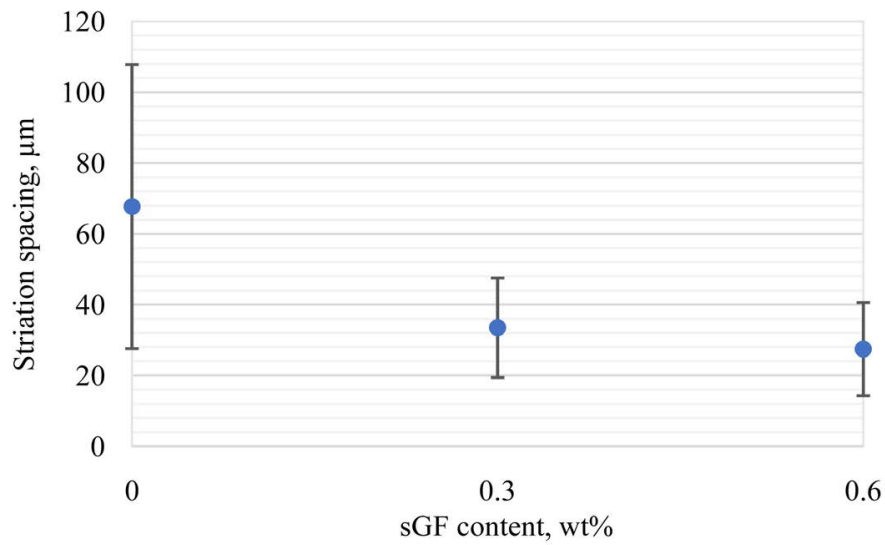

Figure 13. Striation spacing of sMCs with respect to different contents of sGF. 
rate. In other words, the enlargement of number of cycle to failure in sMCs is due to the delay of crack propagation owning to reinforcing effect of sGF. These results indicate that glass fiber plays important role in improving the fatigue life of resin by deflecting micro-crack lines, delaying the propagation of cracks as well as partly dissipating crack growth energy for de-bonding fibers from matrix.

\section{Conclusions}

The sGF was used as reinforcement in VE matrix at low content to investigate its effect on mechanical properties of sMC. Some results can be shown briefly as follows:

1) Submicron glass fiber was well-dispersed in resin by conventional mixing technique. The length of glass fiber after mixing was pretty varied leading to the huge variation of aspect ratio in $\mathrm{VE}$ matrix.

2) Impact resistance of un-notched $s M C$ was decreased with the increase of sGF content in matrix while notched-impact resistance as well as flexural properties, was almost unchanged compared to those of neat resin. Dynamic mechanical analysis indicated the slight increase of elastic behavior and the decrease of damping property in sMC. However, the Mode I fracture toughness improved significantly from $26 \%$ to $61 \%$ while the content of sGF lifted from 0.3 to $0.6 \mathrm{wt} \%$ in composite. Crack growth rate of notch specimens of sMC under tensile cyclic load also considerably degraded. The observation of SEM and lazer microscope shows that evidence of improving fatigue life of sMC is due to deflecting micro-cracks and delaying the propagation of cracks as well as partly dissipating crack growth energy for de-bonding fibers from matrix.

\section{Acknowledgements}

The authors gratefully acknowledge Nippon Muki Co., Ltd. for the financial and material supports provided to this research.

\section{Conflicts of Interest}

The authors declare no conflicts of interest regarding the publication of this paper.

\section{References}

[1] Rao, B.S., Madec, P.J. and Marechal, E. (1986) Synthesis of Vinyl Ester Resins. Evidence of Secondary Reactions by13C NMR. Polymer Bulletin, 16, 153-157. https://doi.org/10.1007/BF00955485

[2] Mullins, M.J., Liu, D. and Sue, H.-J. (2017) Mechanical Properties of Thermosets. In: Guo, Q., Ed., Thermosets, 2nd Edition, Elsevier, Amsterdam, Netherlands, 35-67. https://doi.org/10.1016/B978-0-08-101021-1.00002-2

[3] Hodgkin, J. (2001) Thermosets: Epoxies and Polyesters. In: Jürgen Buschow, K.H., Flemings, M.C., Kramer, E.J. and Veyssière, P., Eds., Encyclopedia of Materials. Science and Technology, 2nd Edition, Elsevier, Amsterdam, Netherlands, 9215-9221. https://doi.org/10.1016/B0-08-043152-6/01660-0 
[4] Varma, I.K. and Gupta, V.B. (2000) Thermosetting Resin-Properties. In: Kelly, A. and Zweben, C., Eds., Comprehensive Composite Materials, Pergamon, London, 1-56. https://doi.org/10.1016/B0-08-042993-9/00177-7

[5] Kandola, B.K., Ebdon, J.R. and Zhou, C. (2018) Development of Vinyl Ester Resins with Improved Flame Retardant Properties for Structural Marine Applications. Reactive and Functional Polymers, 129, 111-122. https://doi.org/10.1016/j.reactfunctpolym.2017.08.006

[6] Jaswal, S. and Gaur, B. (2014) New Trends in Vinyl Ester Resins. Reviews in Chemical Engineering, 30, 567-581. https://doi.org/10.1515/revce-2014-0012

[7] Ku, H., Prajapati, M. and Trada, M. (2012) Fracture Toughness of Vinyl Ester Composites Reinforced with Sawdust and Postcured in Microwaves. International Journal of Microwave Science and Technology, 2012, Article ID: 152726. https://doi.org/10.1155/2012/152726

[8] De LaCaBa, K. (2005) Properties of a Vinyl Ester Resin Modified with a Liquid Polymer. High Performance Polymers, 17, 605-616. https://doi.org/10.1177/0954008305053206

[9] Ullett, J.S. and Chartoff, R.P. (1995) Toughening of Unsaturated Polyester and VinylEster Resins with Liquid Rubbers. Polymer Engineering and Science, 35, 1086-1097. https://doi.org/10.1002/pen.760351304

[10] Orozco, R. (1999) Effects of Toughened Matrix Resins on Composite Materials for Wind Turbine Blades. Ph.D. Thesis, Montana State University, Bozeman, MT.

[11] Marra, F., D’Aloia, A.G., Tamburrano, A., Ochando, I.M., De Bellis, G., Ellis, G. and Sarto, M.S. (2016) Electromagnetic and Dynamic Mechanical Properties of Epoxy and Vinyl Ester-Based Composites Filled with Graphene Nanoplatelets. Polymers, 8, 272. https://doi.org/10.3390/polym8080272

[12] Burchill, P.J. and Simpson, G.J. (1997) Improved Interlaminar Fracture Toughness for Vinyl Ester Resin-Fiber Glass Composites. In: Proceedings of Eleventh International Conference on Composite Materials, Volume 2, Fatigue, Fracture and Ceramic Matrix Composites Gold Coast, Queensland, Australia, 14th-18th July 1997.

[13] Arabli, V. and Aghili, A. (2016) Graphene Oxide/Vinyl Ester Resin Nanocomposite: The Effect of Graphene Oxide, Curing Kinetics, Modeling, Mechanical Properties and Thermal Stability. RSC Advances, 6, 22331-22340. https://doi.org/10.1039/C5RA23731A

[14] Ray, D., Bhattacharya, D., Mohanty, A.K., Drzal, L.T. and Misra, M. (2006) Static and Dynamic Mechanical Properties of Vinylester Resin Matrix Composites Filled with Fly Ash. Macromolecular Materials and Engineering, 291, 784-792. https://doi.org/10.1002/mame.200600097

[15] Auad, M.L., Proia, M., Borrajo, J. and Aranguren, M.I. (2002) Rubber Modified Vinyl Ester Resins of Different Molecular Weights. Journal of Materials Science, 37, 4117-4126. https://doi.org/10.1023/A:1020031701950

[16] Grishchuk, S., Castella, N., Apostolov, A. and Kocsis, J. (2011) Structure and Properties of Vinyl Ester Resins Modified with Organophilic Synthetic Layered Silicates Bearing Non- and Co-Reactive Intercalants. Journal of Composite Materials, 46, 941-947. https://doi.org/10.1177/0021998311413311

[17] Li, Y. (2007) The Development of Sub-Micron Filler Enhanced Polymer Composites. Doctoral dissertation, Nottingham Trent University, Nottingham. http://irep.ntu.ac.uk/id/eprint/192/1/194139 Yalan thesis final.pdf

[18] An, J., Rikukawa, M., Sanui, K. and Ogata, N. (1996) Micro-Composites of 
Poly(Styrene) and Nylon 3 by in Situ Polymerization. Polymer Journal, 28, 496-500. https://doi.org/10.1295/polymj.28.496

[19] Bogomolova, O.Y., et al. (2017) Effect of Adhesion between Submicron Filler Particles and a Polymeric Matrix on the Structure and Mechanical Properties of Epoxy Resin Based Compositions. Mechanics of Composite Materials, 53, 117-122. https://doi.org/10.1007/s11029-017-9645-0

[20] Marquis, D.M., Guillaume, É. and Chivas-Joly, C. (2011) Properties of Nanofillers in Polymer, Nanocomposites and Polymers with Analytical Methods. InTech, London.

http://www.intechopen.com/books/nanocomposites-and-polymers-with-analytical methods/properties-of-nanofillers-in-polymer

[21] DeArmitt, C. (2011) Functional Fillers for Plastics. In: Kutz, M., Ed., Applied Plastics Engineering Handbook Processing and Materials, Elsevier, ^Amsterdam, Netherlands, 455-468. https://doi.org/10.1016/B978-1-4377-3514-7.10026-1

[22] Petit, J. (2001) Fatigue Crack Propagation: Effect of Environment. In: Jürgen Buschow, K.H., Flemings, M.C., Kramer, E.J. and Veyssière, P., Eds., Encyclopedia of Materials: Science and Technology, Elsevier, ‘Amsterdam, Netherlands, 2892-2896. https://doi.org/10.1016/B0-08-043152-6/00515-5 